\title{
EL PASO DE UNA PASTORAL DE "MANTENIMIENTO" A UNA DEL DESARROLLO INTEGRAL DE LA PERSONA
}

\section{The change from a pastoral of "maintenance" to one of the integral development of the person}

\author{
Alfredo Jerí Tafúr \\ Universidad Femenina Sagrado Corazón. alfredojerit@unife.edu.pe \\ ID ORCID: 0000-0003-2168-6315
}

\section{RESUMEN}

El presente artículo es una reflexión académica vinculada al área pastoral, y que involucra a la reflexión teológica ya que tiene que ver estrictamente con la praxis cristiana. Los tiempos de pandemia son una oportunidad para reinventar nuevas y más cercanas estrategias de una pastoral: más encarnada en la historia, más abierta al diálogo y con mayor compresión de la persona y de su integridad. Será importante comprender que los tiempos han cambiado, y que por ello mismo se debe cambiar también el modo de anunciar la fe en Jesucristo. Se ha de pasar de una pastoral reducida a la moral y al cumplimiento de preceptos o normas externas, a una que llene verdaderamente a la persona de una experiencia profunda de Dios.

\section{Palabras clave:}

Persona, integridad, pastoral, cambio, religión.

\begin{abstract}
This paper is an academic reflection within the pastoral area, which involves a theological reflection inasmuch as it has to do with Christian practices and the way to announce the Good Word. Pandemic times provide a good opportunity to reinvent new strategies for pastoral work: ones that are nearer, more engaged in history, open to dialogue and with a better understanding of the person and its integrity. It is important to understand that times have changed and thus the way to announce the faith in Jesus Christ needs to change as well. We need to move from a pastoral focused on morality and the obedience of precepts and external norms, to one that truly fill the person with a deep experience of God. This lively encounter with him will determine the way to understand religion as a relation with God, oneself, and others.
\end{abstract}

\section{Keywords:}

Human being, integrity, pastoral, change, religion. 


\section{INTRODUCCIÓN}

Hoy, en momentos de crisis mundial debido a la pandemia Covid 19, urgen nuevos desafíos y retos pastorales para todo el mundo, pero de manera particular para la Iglesia Católica. Nos encontramos en una sociedad multidiversa, y ante todo lo traído por la globalización, el cientificismo y la deshumanización de la cultura, exige replantearse en clave integradora de la persona, nuevas formas de presentar el mensaje de Jesucristo. Esto será posible si se logra suscitar preguntas para que el ser humano se encuentre consigo mismo, con los demás y con toda la creación. "La fe cristiana es respuesta a los deseos profundos de la persona; por lo mismo, la tarea de la Iglesia está en mostrar a Cristo como la respuesta para que sea palpable cómo la causa de Dios es la causa del hombre" (Sastre, 1999, p. 158).

En cuestiones de pastoral en general, se ha dicho y escrito quizá no tanto como se ha hecho. Los responsables de esta acción eclesial han tenido sus mejores intenciones, pero lo real es que el mensaje de Jesucristo no termina siendo atrayente y cercano para una sociedad tan ajetreada y descentrada como la nuestra. En tiempos de Covid 19, ha sucedido algo particular en propios y extraños, y es que el espíritu religioso se ha hecho más patente, la devoción popular y la vinculación con lo divino y sagrado para alcanzar sanación, consuelo o salvación, se ha hecho más necesaria y útil. Por no pocos años se ha puesto énfasis liviano en la base y el horizonte de nuestra acción pastoral: el Hombre y el Reino, y ni qué decir del centro: Jesús. La encarnación del Verbo, su humanización, su presencia en la historia iluminó y llenó de esperanza a los hombres y mujeres de su tiempo, y con ello a todas las generaciones, de manera especial a los pobres y excluidos. Para ellos, y también para nosotros, el mensaje es claro: "Yo he venido para tengan vida, y una vida en abundancia" (Jn. 10,10). En Gaudium et spes 9, haciendo eco a la referencia anterior dirá: "... las personas y los grupos sociales están sedientos de una vida plena y de una vida libre...", por ello, las propuestas de pastoral tienen que ser respuesta a esos deseos de búsqueda de plenitud del hombre contemporáneo, y que tiene como telón de fondo al mismo Jesús: "La encarnación lleva a la naturaleza humana a su grado más elevado. En Cristo el hombre se realiza con suprema expresión: Forma Dei e Imago Dei (2Cor. 4,4). Por ello Cristo es el modelo, el prototipo de toda perfección humana" (Pablo VI, 1968, p. 186).

Es posible que, en tiempos actuales, en lo que menos se piensa es en lo que puede aportar la teología pastoral a la crisis mundial, sobre todo cuando los ojos están puestos en los últimos avances científicos para encontrar la bendita medicina que detenga esta situación sanitaria adversa. Lo real es que, en miles, millones de hogares se invoca el nombre de Dios, de María Santísima y de muchos Santos a quienes se entregan con piedad y fervor para recibir una ayuda, un consuelo o una esperanza. La fe, independientemente de cuál fuese su creencia, juega un papel importante, ya que devuelve sentido a la vida y rinde respeto ante el misterio de la muerte. Ante esa experiencia humana se hace más presente y actual la teología y sobre todo la acción pastoral de la Iglesia que ayudará a traer consolación en tiempos de desolación.

En líneas generales se podría distinguir dos formas de práctica pastoral: la primera marcada por el enfoque de 
la "cura de almas", que es más de tipo devocional y que se basa en el mantenimiento básico de la fe, de la recepción de los sacramentos, de la exigencia y ceñimiento de la vida a unas normas o a la moral, lo cual no pocas veces devino en un moralismo. La segunda es aquella que procura tener un enfoque más amplio, integral, dinámico y sobre todo humanista de la acción pastoral, aquella que intenta no solo "salvar el alma", sino además desarrollar y asistir más integralmente a toda la persona desde Cristo, el Hijo de Dios que se hizo totalmente humano.

En el avance de una eclesiología actual y dialogante, que busca realizar una acción pastoral integral, antropológica, cristológica, teocéntrica y pneumatológica, no se puede perder de vista la acción de Dios en la historia, quien habló por Jesucristo y que ahora sigue acompañando a la Iglesia mediante el Espíritu Santo. Es necesario, en este momento, contrastar la realidad en que se vive para que la propuesta pastoral tenga más implicancia y repercusión en la vida de los creyentes, y que además el mensaje que se trasmita sea más significativo al hombre concreto, real y sufriente. No cabe duda de que se debe caminar con la historia, para iluminarla y ser fermento en la masa, pero también para impregnar en la persona y en la historia humana nuevas formas de acercarse a lo divino, partiendo de lo efectivamente humano.

Este escrito ha de ser entendido desde un humanismo profundamente cristológico y teocéntrico, en lo que al hombre en tiempos de pandemia y su búsqueda corresponde. Sólo con este planteamiento, que parte de lo humano, se podrá dar respuesta, desde el quehacer pastoral, a las búsquedas de sentido e inquietudes más profundas de la humanidad actual.

[...] El verbo de Dios, por quien todo fue hecho, se encarnó para que, Hombre perfecto, salvara a todos y recapitulara todas las cosas. El Señor es el fin de la historia humana, punto de convergencia hacia el cual tienden los deseos de la historia y de la civilización, centro de la humanidad, gozo del corazón humano y plenitud total de sus aspiraciones... (GS 45).

\section{ANTECEDENTES PARA UN CAMBIO DE PARADIGMAS}

A más de 50 años del Concilio Vaticano II, está aún vigente el llamado a una urgente renovación pastoral y a presentar una Iglesia pobre para los pobres, inculturada y que evidencie en sus acciones su compromiso social y lucha por la justicia. Al parecer, el sueño que tuvo Juan XXIII cuando convocó el concilio se ha vuelto el eje programático y central del modo de proceder del papa Francisco y de muchos sacerdotes, religiosas y laicos quienes con estas motivaciones buscan poner de manifiesto una visión de Iglesia participativa, inclusiva, de desarrollo y de promoción de la persona integral en consonancia con el Evangelio. El giro eclesiológico que intentó la puesta al día de la Iglesia "aggiornamiento" y la nueva manera de entender los signos de los tiempos de pandemia, será lo que hoy motiva a muchos de nuestros pastores a "estar en salida".

El Concilio Vaticano II mostró nuevos caminos de hacer teología, también nuevas maneras de entender a la Iglesia y su misión pastoral. Juan Pablo II, en la Exhortación Apostólica Novo Millennio 
Ineunte 57, animará a toda la Iglesia a mirar los textos que nos dejaron los padres conciliares para que de esta manera "sean conocidos y asimilados como textos cualificados y normativos del magisterio, dentro de la tradición de la Iglesia". De esto también hace eco Benedicto XVI en su carta apostólica Porta fidei (Ns. 10-11-12-24). Queda claro que, con el anuncio de la convocatoria del concilio, Juan XXIII puso un punto de quiebre en el quehacer teológico y pastoral, que a su vez tiene que ser releído y comprendido para un mejoramiento en la praxis eclesial, y sobre todo en tiempos tan cambiantes e inciertos como los actuales. Ese punto de quiebre busca tomar distancia del así llamado antiguo régimen y entrar en consonancia con el devenir de la historia, acercándose a la gente, revalorizando el rol del laico y su misión en la Iglesia y en el mundo. Si en el periodo de cristiandad, todo era entendido y explicado desde la óptica divina, o lo que se conoció como Teocentrismo, con el concilio, siendo conscientes que los tiempos de cambio eran ya inminentes, se aplicó una mirada más uniforme de Dios, del mundo y del mismo hombre. La acción pastoral, con los efectos de esa toma de conciencia de la Iglesia, dio también un giro, que hoy todavía está en actitud de reforma. Gaudium et spes 55 lo expresó de esta manera: "Esto se ve más claro si fijamos la mirada en la unificación del mundo... de esta manera somos testigos que está naciendo un nuevo humanismo, en el que el hombre queda definido principalmente por la responsabilidad entre sus hermanos y ante la historia".

Es pues necesario repensar, replantear y reenfocar la acción pastoral de la Iglesia. Porque hay suficientes herramientas teológicas para hacerlo, partiendo de preguntas como ¿cuántos de nuestros planes y proyectos de pastoral han sido elaborados dejándose tocar por el Espíritu y leyendo los signos de los tiempos? ¿Somos conscientes que el protagonista de la historia es el Espíritu?, ¿y que es Él quien actualiza el mensaje liberador, redentor y salvador de Jesucristo? Y si nos acercamos a los evangelios las preguntas iluminadoras son las siguientes: ¿cómo realizó Jesús su acción pastoral? ¿quiénes fueron los destinatarios de su mensaje? ¿cómo fue su modo de proceder para cambiar la manera de pensar (metanoia) de un pueblo profundamente religioso? ¿Cómo entendía la salvación y cómo la presentó? ¿Qué concepto tuvo del hombre, de su condición y de su dignidad?

Importante es reconocer, que en innumerables ocasiones se ha hecho decir a los planes de pastoral lo que quizá el Espíritu, no hubiera dicho ni hecho. Esto amerita una urgente vuelta a las fuentes, para desde allí "renovar las estructuras caducas que ya no favorecen a la trasmisión de la fe" (AP 364), y poner de manifiesto nuevas formas de acercar la fe; mejor aún, de aproximar la experiencia de Dios a la gente. Una revaloración de la pneumatología en la acción pastoral hará que podamos acercarnos a una lectura real y creyente de la realidad, para desde allí, consigamos que los planes de pastoral sean efectivamente fermento en la masa desde los dolores y sufrimientos de la gente, desde las periferias existenciales o desde el lugar donde habitan los así llamados "descartables".

Será importante que la Iglesia entienda que la propuesta pastoral tiene que ser integradora, y que no puede dejar de ser pneumatológica, antropológica, cristológica y teocéntrica. Así mismo se tiene que ver y entender a la persona como un ser poseedor de múltiples dimensiones y donde convergen una realidad física, psicológica y espiritual. 
Por lo tanto, la asistencia pastoral no puede hacerse únicamente desde la unidimensionalidad del ser sino abarcando todas sus realidades y de manera especial las más urgentes para su vivencia digna.

Al respecto la constitución Gaudium et spes 3 afirmará que "es la persona la que hay que salvar... es por consiguiente el hombre, pero el hombre todo entero, cuerpo y alma, corazón y conciencia, inteligencia y voluntad...".

En ese sentido, y por lo antes expuesto, urge hoy en la Iglesia una acción no solo catequética, de trasmisión de verdades de fe y de religiosidad elemental, que, a decir verdad, al hombre postmoderno casi no le comunica nada, ni motiva nada porque "el género humano se halla en un periodo nuevo de su historia, caracterizado por cambios profundos y acelerados... Tan es así esto, que se puede hablar de una metamorfosis social y cultural, que redunda también en la vida religiosa" (GS 4). Ante esta situación, que se suma a un estado mundial de pandemia, la fe y más concretamente la acción pastoral de la Iglesia han estar a la altura de las circunstancias para transmitir esperanza, consuelo y ánimos, en momentos tan desoladores. Pero también debe ser un canal de ayuda con su testimonio profético a favor de los pobres. De no ser así, quedaría deslegitimada y desconectada de la realidad.

Por ello será necesario profundizar y expresar abiertamente que la novedad del Evangelio, Buena Noticia, es realmente el "prototipo de humanidad" (Trigo, 2018, p. 507). Paradigma que se añora, hasta la certeza de que "... el misterio del hombre sólo se esclarece en el misterio del verbo encarnado [...]. Cristo, el nuevo Adán, en la misma revelación del misterio del Padre y de su amor, manifiesta plenamente al hombre el propio hombre, y le descubre su vocación" (GS 22). Ahora, lo inmediato es no solo bendecirle sino acercar al pueblo golpeado y sufriente, el reconocimiento de su dignidad, para ante su dolor y desesperación hacer nuestros sus fatigas y deseos.

Los que hacemos teología con implicancias pastorales, sabemos que el mensaje de la Buena Nueva del Reino no tendrá repercusión en la vida de los hombres y mujeres mientras se haga indiferente a una lectura creyente y actual de los signos de los tiempos. Una acción pastoral que pierde de vista su contexto real y vital está condenada a pregonar en el desierto. En estos tiempos de crisis mundial habrá que interpretar la historia en perspectiva creyente y actualizar lo dicho por Jesús: "Al atardecer dicen: hará buen tiempo, pues el cielo enrojece. Y por la mañana: hoy seguro llueve, porque el cielo está rojo oscuro. Saben interpretar el aspecto del cielo, ¿y no saben interpretar las señales de los tiempos?" (Mt. 16,2-4).

La vida del hombre, y sus deseos de vivir plenamente, no han sido ajenos a la reflexión y propuestas de la Iglesia a lo largo de su historia. Y cierto es que ha tenido sus propios matices. Mucho o casi todo lo teológicamente planteado sobre el ser del hombre, su realidad y destino, ha estado estrechamente vinculado, muchas veces de manera exagerada y únicamente con lo trascedente. No hubo mala intención en dejar en segundo plano a la humanidad del hombre, con su realidad concreta y vital, pero esto ha dejado secuelas muy serias en la manera, hoy, de presentar una pastoral renovada y alejada de aquella que sólo era de mantenimiento devocional. Aquí resalta el obispo del siglo II, Ireneo de Lyon, quien en su libro "tratado sobre las herejías" (Adversus haereses), tiene una expresión 
muy importante para la teología patrística, pero que en esta ocasión rescata como eje iluminador una manera de entender al hombre, para proponer así una acción pastoral donde se entienda al ser humano como ser integral. "La Gloria de Dios, es el hombre viviente, y la vida del hombre es la visión de Dios" (4,20,5-7).

De esta expresión se desprende claramente que Dios no recibe Gloria cuando el hombre renuncia a su condición humana y a su realidad concreta del más acá. Cuando el hombre vive plenamente su humanidad, y no vive para sobrevivir si no que vive desarrollando sus capacidades y potencialidades de manera integral, al estilo de Jesús, entonces dará la Gloria a Dios. La constitución Gaudium et spes 21 afirma que "todo hombre resulta para sí mismo un problema no resuelto", es decir, somos un misterio cargado de complejidad pero que la realidad más profunda se ve develada en el arquetipo y paradigma de la humanidad de Jesús de Nazaret. Por eso, "el que sigue a Cristo, hombre perfecto, se hace a sí mismo más hombre" (GS 41).

La voluntad de Dios será pues salvaguardar, dignificar y promover el privilegio que tiene el hombre ante toda la creación y responder a su búsqueda de sentido de manera integral. La Gloria de Dios, en este sentido, es ver al hombre desarrollarse lo más que pueda, creciendo no solo desde su dimensión espiritual sino explotando al máximo todos los recursos con los que cuenta, porque los talentos se desarrollan y crecen en la medida que entran en una dinámica que les permita ejercitar esa capacidad. (Mt 25, 14-30). El Señor ha proporcionado dones, talentos, recursos que no pueden ser considerados como los pasivos de la vida. Contrariamente, será lo que de Gloria a Dios el movimiento de ese recurso, la dinámica de los talentos y el desarrollo de las capacidades y potencialidades, de las dimensiones y facultades, de la búsqueda de ser cada día más y mejor persona.

En ese sentido, la teología pastoral tiene el gran reto de alejarse de un anuncio, por así decirlo, que enfocó muchas veces la salvación desde el punto de vista únicamente espiritual, y hacer que el mensaje de Jesús abarque a la persona en su conjunto, como Él mismo lo hizo. Y así se podrá VER hic et nunc ("aquí y ahora"), DISCERNIR hic et nunc, y PROPONER hic et nunc una evangelización más plenificante, más humana, más existencial, y que busca contraponer un tipo de pastoral para nuevos tiempos, con nuevos retos y en tiempos de pandemia.

No se trata, pues, de repetir cansinamente las verdades de fe. Se trata de entender la profundidad de la fe y desde allí plantear una reforma que busque establecer nuevos canales de evangelización, "en su ardor, en su método y en su expresión" (Juan Pablo II, 1983), y que es lo que el concilio vislumbró en una propuesta pastoral renovada y que hoy sigue siendo una exigencia.

\section{ECLESIOLOGÍA PROPUESTA POR EL CONCILIO VATICANO II}

La eclesiología de comunión presentada por el Vaticano II, buscó ser la contraparte o el equilibrio de lo que hoy ya no tiene vigencia y que se conoce como el "eclesiocentrismo", desde donde por mucho tiempo la Iglesia se centró y entendió sólo a sí misma como institución exclusiva garante de la fe y de la salvación, "extra Ecclesiam nulla salus". En ese contexto, se puede afirmar que la "pastoral" vigente fue mayormente la del miedo y la del cumplimiento riguroso de preceptos morales; claro está 
que en tiempos pasados fue suficiente mantener la piedad y la religiosidad de la comunidad con una acción "pastoral de mantenimiento", de devociones, o lo que se conoce como una pastoral de cura de almas. El giro eclesiológico del Vaticano Il fue clave no solo para entender la misión de la Iglesia en el mundo moderno sino para actualizar el mensaje universal de salvación, y para otorgarle mayor vigencia a la propuesta del anuncio de la Buena Nueva que consiste, de manera categórica, en plenificar la vida de los hombres. El aggiornamento que trajo el concilio volcó sus principales esfuerzos para poner la Iglesia al día. El papa Juan XXIII entendió que los tiempos habían cambiado y no era posible seguir en el régimen de una religiosidad pasiva: "Juan XXIII parece haber percibido, al menos indicios de lo que estaba en juego, y ciertamente, después de inaugurado el concilio, los obispos tomaron en consideración la situación [...] y afrontaron la "nueva era" en la que el mundo había entrado" (Spadaro y Galli, 2016, p. 111 ).

La novedad del desarrollo conciliar sorprendió a propios y extraños ya que la impronta o estilo del Vaticano II tuvo un talante distinto a los concilios anteriores; aquellos surgieron en ambientes de controversia y su objetivo era acuñar verdades de fe concernientes a la dogmática, o para hacer espíritu de cuerpo frente a reformas surgidas dentro de la Iglesia, pero este tuvo un carácter pastoral actualizado. Claramente urgía entrar en consonancia con los nuevos tiempos, la misma exigencia que tenemos hoy, solo que esto se decidió hacer desde la más alta jerarquía.

No obstante, aunque se evidencie que es necesario re-direccionar los enfoques de la acción pastoral de la Iglesia, también se puede evidenciar que a nada se podrá llegar, si no se logra oír las búsquedas, inquietudes y el conocimiento más cercano de las realidades de las bases. El teólogo Casiano Floristán dirá que "hay católicos para los cuales el Vaticano II ha sido un acontecimiento necesario, importante y trascendente en la vida de la Iglesia, que ha operado un cambio profundo en la comprensión de la acción pastoral de la Iglesia..." (1990, p.158). Ciertamente, en las últimas décadas se ha dejado notar un cambio significativo, pero no ha sido suficiente porque la sociedad, el pensamiento y el hombre están en un cambio realmente vertiginoso y más aún en tiempos de pandemia la pastoral no puede detenerse.

Será importante un enfoque pastoral dinámico y donde el hombre sea entendido de manera integral. Es clave tomar distancia de las miradas reduccionistas que entienden al hombre como ser unidimensional. Así, se pretende hacer un enfoque más amplio e integral de la persona y de las implicancias que estas tienen. Solo de esta manera se podrá enfrentar, desde la propuesta eclesial, una pastoral renovada y acorde a la exigencia del mundo presente que sufre esta pandemia, ya que "todo intento de dar prioridad a la espiritualidad y el pietismo desencarnados al margen del hombre, de su vida en el mundo y de la problemática social, es vaciar de contenido la fe cristiana" (Margallo, 2003, p. 71).

Concebir y tratar de entender la complejidad de la persona desde una mirada exclusivamente espiritual, es un riesgo que afecta de manera radical la praxis eclesial. Por esta razón, hay que volver al evangelio buscando su comprensión de persona y cómo Jesús entendió a los hombres y mujeres de su tiempo. Esto lleva a entender las implicancias que acarrean una mejor 
comprensión del hombre con una mirada más amplia. Y lo que es importante: auxiliado y en diálogo con las disciplinas que permitan un mejor acercamiento a su realidad compleja y a sus deseos naturales de búsqueda y sentido.

Vigil afirma que el tema central del Vaticano II ha sido la Iglesia y su misterio (1985, p.19). Efectivamente, la pregunta que inspira los nuevos giros eclesiológicos será la pronunciada por Pablo VI: "¿̇glesia, ¿qué dices de ti misma?". Esta y otras preguntas han generado implicancias positivas que el concilio tradujo en documentos, y que son fruto de un camino de renovación, a nivel bíblico (Dei Verbum), litúrgico (Sacrosanctum concilium), eclesiológico (Lumen gentium), misionero (Ad gentes), pastoral (Gaudium et spes) y ecuménico (Unitatis redintegratio) (Vigil, 1985, p. 25).

Hay que remarcar que la teología pastoral, promovida en el Vaticano II y que el día de hoy también se va reinventando, tiene su fuente en la comprensión acertada de la eclesiología de comunión en la que se considera una nueva forma de relación entre clérigos, religiosos y laicos.

Esto representa un avance notable para la Iglesia; se vivió tiempos de reforma en la manera de entender a la Iglesia, su misión, pero también al Hombre. De esta forma, se entenderá que los laicos no solo pertenecen a la Iglesia, sino que son la Iglesia gracias al fundamento que nos da el bautismo. Así, Juan Pablo II en la Exhortación apostólica postsinodal Christifideles laici pondrá de manifiesto esta vinculación divina común que nos da el sacramento, además de estar llamados a la plenitud de la vida cristiana y a la perfección de la caridad. En ese sentido, todos, estamos llamados a ser luz del mundo y a transparentar en nuestras acciones la bondad de Dios.

\section{EL PAPA FRANCISCO Y SU MANERA DE ENTENDER LA ACCION PASTORAL}

Una de las novedades del magisterio del Papa Francisco es aquella que pone en el centro de su mensaje al sujeto, al hombre, a la persona. Así mismo, aborda temas que tienen que ver con cuestiones sociales o políticas porque en medio de esa realidad está en juego la dignidad de la persona. Es claro que su manera de proceder está en consonancia con los nuevos tiempos. Se puede afirmar, que, como buen jesuita, sabe ver y discernir los signos de los tiempos, y desde esa lectura creyente de la realidad, actualiza el mensaje de Jesucristo para seguir haciendo eco a las intuiciones del concilio.

Los aires frescos que llegaron a San Pedro, iniciados por Juan XXIII, no han logrado extinguirse y su tarea inacabada sigue mostrando continua renovación, principalmente en el magisterio del papa Francisco y más concretamente en lo que a pastoral se refiere en tiempos de pandemia. En el número 26 de la exhortación apostólica Evangelii gaudium, Francisco cita el decreto Unitatis Redintegratio para evocar una propuesta eclesial de reforma vinculada al concilio:

El Concilio Vaticano II presentó la conversión eclesial como una apertura a una permanente reforma de sí por fidelidad a Jesucristo [...] Cristo llama a la Iglesia peregrinante hacia una perenne reforma, de la que la Iglesia misma, en cuanto institución humana y terrena, tiene siempre necesidad" (UR 6).

El papa Francisco, con la valoración que da a la eclesiología, entendida como pueblo de Dios y comunión, va en la misma línea del concilio, poniendo 
ahora especial énfasis en el desarrollo y promoción integral de la persona, especialmente de los más vulnerables y de sus necesidades no solo espirituales. De esta forma, se puede decir que Francisco va en la línea más pura del concilio y busca romper esquemas tradicionales de evangelización. Para Francisco, la conversión eclesial no es sólo el cambio que se debe suscitar al interno de la Iglesia, tema y pugna que han sido punto de discusión en los últimos cincuenta años, sino que será importante tener en cuenta a la persona de manera integral. Ese será el inicio de su reflexión pastoral: "De nuestra fe en Cristo hecho pobre, y siempre cercano a los pobres y excluidos, brota la preocupación por el desarrollo integral de los más necesitados" (EG 186).

Así pues, ha de entenderse con claridad que la propuesta evangelizadora que hace la Iglesia, como responsable de la actualización del mensaje de Jesucristo, tiene la imperiosa necesidad de abordar al hombre en sus múltiples dimensiones, hacer que la Buena Noticia se viva aquí y ahora como antesala del Reino y que los planes de pastoral ayuden en esa tarea. "Sabemos que Dios quiere la felicidad de sus hijos también en esta tierra, aunque estén llamados a la plenitud eterna, porque Él creó todas las cosas para que las disfrutemos (1 Tim 6,17) y para que todos puedan disfrutarlos" (EG 182). La manera tan clara y precisa como el papa Francisco genera un clima de reforma en el ámbito pastoral se da porque continuamente está bebiendo de las fuentes de las Sagradas Escrituras abordando a la Iglesia y su misión, sin distraer su mirada de Jesús. "Jesucristo también puede romper los esquemas aburridos en los cuales pretendemos encerrarlo [... . Cada vez que intentamos volver a la fuente y recuperar la frescura original del evangelio, brotan nuevos caminos" (EG 11).
Es preciso remarcar la importancia de Bergoglio en Aparecida, para contextualizar la pertinencia de un cambio de paradigma pastoral y la necesidad de reorientarla, a fin de que sea más efectiva su acción en tiempos de pandemia. Su participación en la V Conferencia General del Episcopado Latinoamericano (2007) fue crucial, ya que en ella revaloraron la acción misionera de la Iglesia subrayando la necesidad de pasar "de una pastoral de mera conservación a una pastoral decididamente misionera" (DA 370). En tal asamblea surgieron unas preguntas interesantes. ¿Quién es el sujeto de la acción misionera y evangelizadora de la Iglesia? ¿Cómo entiende la Iglesia el fin de su práctica eclesial? ¿Qué dimensión del hombre hay que tener en cuenta para el anuncio de la propuesta salvífica? ¿Un mensaje de salvación, para quién? Esta y otras cuestiones tienen su resonancia e implicaciones en cuestiones pastorales hoy más que nunca en tiempos de pandemia:

Ante todo, hay que decir que en el anuncio del Evangelio es necesario que haya una adecuada proporción, un nuevo equilibrio, como lo ha dicho el papa. Esta proporción tiene que ver con los acentos que se ponen en la predicación... que expresan el corazón del Evangelio (Fernández y Rodari, 2014, p. 57).

No cabe duda de que en el centro del mensaje de Jesucristo está el hombre. No hay ser en la creación de Dios que posea la dignidad humana de ser persona. Después del Concilio Vaticano II, el lenguaje para mencionar la acción pastoral de la Iglesia se fue haciendo más cercano y actual. De esta manera, hoy se tiene la suficiente información escrita para renovar nuestro anuncio. Al menos así se "clarificó la 
relación entre evangelización y liberación histórica, entre anuncio del evangelio y desarrollo integral, entre Reino de Dios y promoción humana" (Papa Francisco, 2014, p. 21).

\section{JESÚS Y SU MANERA DE HACER PASTORAL}

A Jesús le importa el hombre integral; y a la gente de su tiempo les da un mensaje de esperanza, de inclusión, reivindicando así las condiciones más inhumanas e injustas, incorporando a la gente de las periferias al centro de su predicación. Para Jesús no es suficiente anunciar la Buena Nueva con palabras, será clave que su discurso esté acompañado de acciones con un profundo compromiso con la persona, entendida integralmente. Por ello su mensaje no se centró exclusivamente en el consuelo espiritual, sino que buscó hacer que el anuncio de salvación quede y sea evidenciado en la vida misma del hombre. El numeral 269 de Evangelii gaudium dice:

Jesús mismo es modelo de esta acción evangelizadora [...] Si habla con alguien, miraba a sus ojos con una profunda atención amorosa [...] Lo vemos accesible cuando se acerca al ciego del camino y cuando come y bebe con los pecadores [...] Lo vemos disponible cuando una mujer prostituta unge sus pies o cuando recibe en la noche a Nicodemo.

Claramente ha dejado un modo de anunciar la Buena Noticia, que no puede ser entendida alejada y ajena a la existencia humana; y, además, entiende a la salvación con elementos que tal vez no han sido tomados en cuenta hasta ahora: me refiero a la integralidad de la persona con respecto a la salvación.
Para que la práctica pastoral se revitalice en tiempos de pandemia a modo de desierto, hace falta, entre otras cosas, una cuestión categórica: volver a las fuentes, dejarse interpelar por el modo de proceder de Jesús y no perderle de vista cuando se tenga que hacer una lectura creyente de la realidad. Él ya ha dado una misión: "vayan y hagan ustedes lo mismo" (Mt. 28,19-20). ¿Será que no se está prestando atención a las palabras de Jesús? ¿Será que las redes están siendo echadas al mar en nombre de prejuicios propios, de intereses propios, de limitaciones propias? El cansancio de la faena nocturna no es fructífero porque se quiere pescar poniendo la confianza solo en la fuerza humana. "Maestro, estuvimos toda la noche intentando pescar, sin conseguir nada; pero en tu nombre, sólo porque tú lo dices, echaré las redes..." (LC. 5,1-11).

La pastoral de Jesús tiene un elemento teológico y práctico que no puede pasar desapercibido y que amerita rescatar, y es que Él vivía lo que predicaba. Cuidó a su rebaño y murió en la cruz a consecuencia del estilo de vida y de la forma como vivió. "Yo soy el Buen Pastor y conozco a mis ovejas", será la expresión que resalte más bellamente la manera de proceder del Maestro. Se puede decir que ahora la única diferencia es que no tiene que dejar las noventa y nueve para salir en busca de la oveja perdida, sino salir en búsqueda de las noventa y nueve que están fuera, hambrientas, sedientas, sin trabajos, enfermas y sin aliento.

Esto exige, sin lugar a duda, la búsqueda de caminos o una metodología catequética y evangelizadora que permita suscitar en el creyente y también entre los que forman parte del rebaño, un profundo sentido de pertenencia a su pastor. Todo es un reto que exige como requisito 
el cambio de mentalidad (metanoia), empezando por la misma estructura jerárquica. Y más concretamente, por aquellos que se resisten a dejar prácticas de una religiosidad orientada a lucir escondiéndola como el talento, su fe intacta, semejantes al sujeto de la parábola que Jesús reprobó, por preferir de modo exclusivo el necesario, aunque insuficiente mantenimiento de la fe.

Aún el día de hoy, mientras el mundo y su historia van, por un lado, nuestro mensaje y prácticas pastorales van por otro. Esa disociación que entendía a la Iglesia como sociedad perfecta ha causado un daño que poco a poco habrá que reparar desde una propuesta pastoral más integradora, dialogante y evangélica. Este reto resuena desde la teología, con sus innumerables documentos eclesiales que invitan a la conversión pastoral, a la escucha atenta de los signos de los tiempos, a la nueva evangelización, a volver a las fuentes, a redescubrir la persona novedosa de Jesús. No es suficiente con hacer teología, o lo que es peor aún, planificar nuestra acción pastoral desde el escritorio; urge una teología de mística, de recogimiento, de escucha y de silencio. Solo de esta manera nuestras propuestas de evangelización serán más fructíferas y dejarán de ser, únicamente, una reflexión humana sobre Dios. Urge así una "teología de rodillas" (Balthasar, 1964, p. 242), una "mística de ojos abiertos" (Metz, 2013, 86), una pastoral con los pies en la tierra y con la mirada en el hombre y en Jesús.

La salvación que proclama la fe cristina más genuina equivale a la humanización plena. Jesús es el hombre nuevo y abre camino a la humanidad nueva. Este es el mensaje específico sobre la doctrina cristiana sobre la encarnación de Dios en la persona de Jesucristo. Salvarse es llegar a ser plenamente humano, liberarse de toda la inhumanidad que atraviesa nuestra historia (Martínez 2019, pp. 321-322).

La teología pastoral tiene que abordar el ser del hombre a partir de un diálogo interdisciplinar y con una mirada multidimensional, y sólo acercándonos de manera seria al misterio del hombre se podrá ofrecer la fe como un elemento de ayuda a la realización integral de su persona. En ese sentido, en tiempos de pandemia, nuestra práctica pastoral ha de ser fundada en la manera cómo entendía Jesús a la persona y cómo abordó sus deseos de liberación y redención. Habrá que preguntarnos ¿cuál es el rol de la soteriología en nuestra acción pastoral actual? ¿Esperamos para el hombre, únicamente, una salvación escatológica? La constitución Gaudium et spes nos dejará claro que es necesario recurrir a otras disciplinas para hacer que nuestro mensaje sea eficaz, eso implicará hacer un diálogo académico que traerá consigo repercusiones prácticas para hacer razonable nuestra esperanza (1 Ped. 2,15). Las expresiones del papa Francisco son claras al respecto:

Prefiero una iglesia accidentada, herida, manchada por salir a la calle, antes que una iglesia enferma por el encierro y la comodidad de aferrarse a las propias seguridades. No quiero una iglesia preocupada por ser el centro y termine clausurada en una maraña de obsesiones y procedimientos (EG 49).

De esta manera quedaría evidenciado que necesitamos cambiar no solo de lenguaje o solo de metodología, cuando 
de anunciar la Buena Nueva se trate, sino de empezar a tener espacios formativos para el clero, los religiosos y los laicos con una nueva manera de entender la acción pastoral, ya no únicamente como cura de almas, sino entender a la evangelización como espacio de desarrollo integral de la persona y de la comunidad cristiana. Si hasta este punto logramos acercarnos al misterio del hombre, que es asunto nuclear para la evangelización, entonces las posibilidades de entender una pastoral renovada irán madurando.

\section{REFERENCIAS BIBLIOGRÁFICAS}

Alberigo, G. (2005). Breve historia del concilio vaticano II: 1959-1965. Sígueme.

Atott, J. y Grau, José. La evangelización y la Biblia. 2a ed. Pensamiento Evangélico. Barcelona: Ediciones Evangélicas Europeas, 1973.

Benzo, M. (1978) Hombre profano hombre sagrado. Tratado de antropología teológica. Cristiandad.

Benzo, M. Pastoral y Laicado a la luz del vaticano II. Madrid: Acción Católica.

(1997). Transmitir el evangelio de la verdad. Diakonia fidei 3. Edicep.

Blázquez, Ricardo. (2013). Del Vaticano II a la Nueva Evangelización. Sal Terrae.

Bosch, J. (2001). Retos de la Iglesia ante el nuevo milenio. (Cátedra Chaminade 6). PPC 2001.

Bovis, A. (1968). Vivir la fe. (Colección de pastoral catequética. Marova.

Candela, J. (1965). El apostolado de los seglares. Decreto del Concilio Vaticano II. Edición bilingüe. PPC.

Carvazos-González, G. (2014). Más allá de la devoción: la vida espiritual, la justicia y la liberación cristianas. EVD.

Congar, Y. (2014). Por una Iglesia servidora y pobre.

Cordovilla, A. (2012). Crisis de Dios y crisis de fe: volver a lo esencial. Sal Terrae.

Delicado, J. (1975). Renovación: Por un cristianismo joven. (Pastoral Aplicada 84). Propaganda Popular Católica.

Estrada, J. (1992). La espiritualidad de los laicos: En una eclesiología de comunión. (Biblioteca de Teología 19). Paulinas.

Floristán, C. (1990). Vaticano II. Un concilio pastoral. Sígueme.

Floristán, C. y Useros, M. (1968) Teología de la acción pastoral. Editorial Católica.

Gaboriau, F (1970). El giro antropológico de la teología de hoy. Herder.

Gelabert, M. (1983). Experiencia humana y comunicación de la fe: ensayo de teología fundamental. Ediciones Paulinas.

Gonzalez, L. (1994). Evangelizar en un mundo postcristiano. Sal Terrae.

Gutiérrez, D. (1995). La humanidad de Jesús de Nazaret. (Teología siglo XXI 17). San Pablo.

Infiesta, J. (1970). La Iglesia ha cambiado siempre. (Pastoral Aplicada 67). Propaganda Popular Católica. 
Lacoste, J., y Checchi, T. (2010). Experiencia y absoluto: Cuestiones que se encuentran en discusión sobre la humanidad del hombre. Sígueme.

Ladaria, L. (1987). Antropología teológica. UPCM.

Margallo, F. (2003). Compromiso político en el Vaticano II. Raíces humanas de la esperanza cristiana. San Pablo.

Maritain, J. (1966). Humanismo integral. Problemas temporales $y$ espirituales de una nueva cristiandad. Carlos Lohlé.

Martínez, F. (2005) Creer en Jesucristo. Vivir plenamente. Cristología y seguimiento. Verbo Divino.

Martínez, F. (2012) Creer en ser humano, Vivir humanamente. Verbo Divino.

Mena, J. (2017). La conversión pastoral en los manuales de teología pastoral españoles (1995-2005): Criteriología teológica y hermenéutica desde el paradigma de la complejidad. ISTIC.

Metz, J. (2013). Por una mística de ojos abiertos. Cuando irrumpe la espiritualidad. Herder

Obregón, L. (1974). Evangelización liberadora: Evangelizar y educar la $\mathrm{Fe}$, tareas de nuestro Tiempo. ¿Cómo realizarlas? (Cuadernos de Pastoral 73-74). Edicep.

PAPA FRANCISCO (2014), La alegría del evangelio. Claves y propuestas para la comunidad evangelizadora. PPC.

PAPA FRANCISCO (2015). Laudato si: Carta Encíclica. BAC-Documentos. BAC.
PAPA JUAN PABLO II (1983), Discurso a la asamblea del CELAM.

PAPA PAULO VI (1968), Jesucristo, Iglesia y Fe. Comentario de Teología pastoral a la luz del Concilio Vaticano II. Sígueme.

Perea, J. (2015). Del Vaticano II a la Iglesia del Papa Francisco: cincuenta años de postconcilio. (Colección GS). PPC.

Placer Ugarte, F. (2006). Remodelación pastoral renovación eclesial a los 40 años del Vaticano II. Nueva utopía.

Rojano, J (2002). La acción pastoral en una cultura postmoderna. Algunas propuestas desde la teología de Jon Sobrino.

Sahagún, J. (1988). El hombre, ¿quién es? Antropología cristiana. (Biblioteca básica del creyente. Serie magenta). Sociedad de educación Atenas.

Salas, A. (1993). El Evangelio de Juan. Jesús: creador de una humanidad nueva. Paulinas.

Silva, S. (2014). La palabra de Dios en la vida y pastoral de la iglesia. Verbo Divino.

Spadaro, A., Galli, C., Borras, A. y Leonetti, M. (2016). La reforma y las reformas en la Iglesia. Sal Terrae.

Stein, E. y Mardomingo, J. (2002). La estructura de la persona humana. Biblioteca de Autores Cristianos.

Tillard, J. (1991). Iglesia de Iglesias. Eclesiología de comunión. Sígueme.

Fecha de recepción: 31-04-2020

Fecha de aceptación: 02-05-2020 